\title{
Relationship between Perceived Stress, Psychological Wellbeing and Emotional Competence among Baccalaureate Nursing \\ Students: an Egyptian Sample
}

\author{
Ola Ahmed Rashad Lachine, Assistant professor \\ Psychiatric Nursing and Mental Health Department, Faculty of Nursing,Alexandria University, Egypt \\ HebaShafik Ibrahim Mohamed, Lecturer \\ Psychiatric Nursing and Mental Health Department, Faculty of Nursing,Damanhour University, Egypt \\ HebaShafik Ibrahim Mohamed, Assistant Professor \\ Psychiatric Nursing, College of Nursing,King Saud Bin Abdullazize for Health Science University, Saudi Arabia \\ Rasha Salah Eweida, Lecturer \\ Psychiatric Nursing and Mental Health Department, Faculty of Nursing,Alexandria University, Egypt
}

\begin{abstract}
Nursing education is acknowledged as one of the stressful and emotionally demanding profession. Stress among nursing students is an inevitable issue that might lead to poor psychological wellbeing. Having a good emotional competence helps university nursing students to decrease their stressand enhance their psychological well-being. Aim: this study was aimed to determine the relationship between the perceived stress, psychological wellbeing and emotional competence among baccalaureate nursing students. Design: A descriptive correlational research design was used in this study. Baccalaureate nursing students who were enrolled at Psychiatric Nursing and Mental Health coursewere the study subjects. Their number amounted 135 students. Four tools were used namely; Bio-socio demographic data structured interview schedule, Ryff's Psychological Wellbeing (RPWB) scale, The Emotional Skills/Competence questionnaire and Perceived Stress Scale (PSS).Results:A positive significant relation between the students' psychological well-being and their Emotional competence was noted and there was a negative significant correlation between them and students' perceived stress.It can be concluded that nursing students have high level of stress and their emotional skills/competence in addition to their psychological well-being can help them to decrease their level of stress. Implementation of emotional hygiene program, to teach the nursing students to care for their own emotions and didn't leave them injured or untreated is recommended.
\end{abstract}

Key words: Stress, Psychological well-being. Emotional competence, Nursing students.

DOI: $10.7176 / \mathrm{JHMN} / 68-09$

Publication date: November 30th 2019

\section{Introduction}

Nursing education is acknowledged as one of thestressful and emotionally demanding profession. ${ }^{(1)}$ Baccalaureatenursing students frequently encounter great deal of stressors such as heavy load of required assignments and examinations, interpersonal difficulties, family or financial problems, physical and mental health issues, inadequate support, and poor coping skills.(2) Moreover, nursing students are involved in practical experience that is highly stressful. ${ }^{(3)}$ Clinical training in psychiatric hospitals exposes the nursing students to an experience that is so different from other previous nursing experiences. The students have to struggle tobuild relationship with patients who havedifficulties trusting others, engaging in communication with patients who have deep feeling of insecurity. In addition, one ofthe unfortunate facets of working in psychiatric setting is the exposure to patients' aggression and violence.

Perceived stress is conceptualized as "the extent to which a situation in life is appraised as stressful and related effort made by the individual to deal with the personal and environmental challenges". $\left.{ }^{4}\right)$ There is considerable evidence that stress, anxiety, and depression are higher among nursing students and these rates continue to remain elevated when these students become nurses in the future. ${ }^{(5-8)}$ Researches also confirmed that medical and health care students are at higher risk of mental disorders compared to their colleagues in other academic studies. This may be due to their exposure to emotional pressures arising from facing various human sufferings. ${ }^{(9-11)}$ A research conducted to assess the perceived stress among Egyptian nursing students, revealed that stressors were reported by $97.3 \%$ of the studied students and the number of stressors reported bystudents ranged 
from 0 to 13 , with a mean of $4.6 \pm 2.5$. The reported rate of the occurrence of different stressful events ranged from as low as $9 \%$ - for the "death of a family member" to a high of $82.6 \%$ for "fear of the future". The five most frequently reported stressors were fear of the future, self-reported anxiety and depression, increased class workload, accommodation problems and congested classrooms. ${ }^{(12)}$

Similarly, the psychiatric lecturers and demonstrators who teach and guide the students through their clinical experience report dealing with different students who are emotionally fragile and in need for psychological support, counseling and even referral. This might interfere with the requirements of this specialized area of nursing practice,that demand primarily psychiatric nurses who can impart feeling of safety and security to their patients and help them deal with their problems. Thus, undergraduate learning may be compromised due to stress and related reaction. ${ }^{(13)}$

Stress among nursing students is an inevitable issue in nursing education that might lead to poor psychological wellbeing. ${ }^{(14,15)}$ Psychological well-being refers to "the extent to which people feel that they have meaningful control over their life and their activities". (16) It is based mainly on two vital approaches, namely the hedonic approach related to subjective wellbeing and happiness and the eudemonic approach, which is the connection between psychological well-being and human potential development. ${ }^{(17)}$ Studies showed that better management of daily stress is significantly related to higher levels of psychological well-being, which enables the person to face challenges and discover particular ways to react to life events. ${ }^{(18-21)}$

Emotional competence is also fundamental to the nursing profession. ${ }^{(22)}$ In order to, provide a high-quality care,nurses must be able to recognize, handle, manage, and understand emotions not only in themselves but also in others. ${ }^{(23)}$ Emotional competence is "the ability to identify and manage one's emotions. This includes knowing how to nourish one's emotional state, take turns, delay gratification, and cope with failure and loss. It also involves knowing how to control impulses, use good judgment and adapt emotions in response to others' emotions and reactions". (24)

During their academic journey, university nursing students are challenged with different stressors that can plague themwith crippling bouts of stress. ${ }^{(25)}$ Emotional competence has been found to play a pivotal role in enriching the nursing students with emotional skills. ${ }^{(26)}$ Researches revealed that the students with effective emotional skills have more positive attitudes to learning and social experiences. They are easily accepted by their peers, more adaptable and confident, and more likely to be academically successful. ${ }^{(27-29)}$ Furthermore, Parker et al. (2004) investigated the association between emotional competence and academic achievement and foundthat emotional competence is a significant predictor of academic success for students of all grades without any gender differences. ${ }^{(30)}$

On the other hand,the inability to manage and respond to stress effectively is believed to be among the primarily factors interfering with the academic achievement, and productivity. ${ }^{(31)}$ This link leads to an increased concern for studying the effect of psychological wellbeing and emotional competence on the students' perception or judgment of the stressfulness of the situations faced. Accordingly, there is a need to examine whether psychological wellbeing and emotional competence can affect the level of perceived stress among nursing students. Such knowledge could shed the light on the importance of equipping nursing students with the necessary skills to adapt to the stressors of the university education.

Furthermore, it has been postulated that the psychological well-being of nursing students is an important component in the training and development of future nurses. ${ }^{(32-35)}$ The more psychologically healthy the nursing students are, the more likelytheywill be productive and successful in their academic and clinical training. ${ }^{(32)}$ Thus, healthy and productive nurses will be able to handle the challenges of the nursing profession and provide quality patient care contributing positively to the nursing profession. ${ }^{(33)}$ Accordingly, there seems to be a great need to study the relationship between perceived stress, psychological wellbeing and emotional competence among baccalaureate nursing students.

\section{Aim of the Study:}

This study aims to determine the relationship between the perceived stress, psychological well-being and emotional competence among baccalaureate nursing students

\section{Research Question:}

- Is there a relationship between perceived stress, psychological well-being and emotional competence among 
baccalaureate nursing students?

\section{Methodology}

\subsection{Research Design:}

A descriptive correlational research design was used in this study.

\subsection{Setting:}

The study was carried out at the Psychiatric Nursing and Mental Health Department, Faculty of Nursing, Alexandria University. The Faculty of Nursing follows the credit hours system in which the curriculum is distributed along eight semesters, in addition to an internship year. psychiatric nursing and mental health is taught in the seventh and eighth semester (depending on students' registration, they attend in either semester). The duration of this educational experience is 15 weeks. Clinical training is given 9 hours/week for 6 weeks and the theoretical contents are taught 3 hours/week for 15 weeks.

\subsection{Subjects:}

The subjects of this study comprise all nursing students (135 students) attending Psychiatric Nursing and Mental Health at the time of data collection.

4.4 Tools:Four tools were used to collect data for this study:

\section{Tool I: Bio-sociodemographic data structured interview schedule:}

This tool was designed to elicit information related to biosocio-demographic data of the students (name, age, sex, residence), and their Grade Point Average (GPA).

\section{Tool II: Ryff's Psychological Wellbeing (RPWB) scale:}

It was developed by Ryff(1989)to assess the students' psychological wellbeing. It comprises 42 statements, grouped into six areas of psychological wellbeing:(autonomy, environmental mastery, personal growth, positive relations with others, purpose in life, and self-acceptance). Respondents rate eachstatement on a scale of 1 to 6 , with 1 indicating strong disagreement and 6 indicating strong agreement.Scores are reversed for 21 negatively stated items.

Responses are totaled for each of the six areas. For each area, a high score indicates that the respondent has a mastery of that area in his or her life. Conversely, a low score shows that the respondent struggles to feel comfortable with that particular concept. These measures have adequate reliability (Alpha $=0.70-0.84) .{ }^{(36)}$

\section{Tool III: The Emotional Skills and Competence questionnaire:}

This is 45- item self- report, developed by Taksic (2002), to assess the individual difference in emotional skills or competence. It is divided into three subscales: a) "The Perceive and Understand emotions scale"composed of 15 items, b) "The Express and Label emotions" scale has 14 items, andc) "The Manage and Regulate emotions scale" has 16 items. Subjects were asked to rate the items at 5-point scales (1-never, 2-seldom, 3- occasionally,4-usually, 5 -always). ${ }^{(37)}$ For all of these subscales, a mean score will be calculated. The higher the score, the greater the level of the measured constructs.

Tool IV: Perceived Stress Scale (PSS):

The Perceived Stress Scale (PSS) was developed by Cohen et al. (1983) as a 14-item instrument designed to measure the degree to which situations in a person's life are appraised as stressful. This scale was modified intoa shorter version of 10 items by Cohen\& Williamson (1988) to allow assessment of perceived stress without any loss of psychometric quality. This instrument has been used extensively with various population, including college students, adolescents, and professional nurses. The responses are rated on a five-point Likert scale ranging from (0) indicating "never" to (4) indicating "very often". Four statements from the scale are negatively stated and reversely scored. ${ }^{(38)}$

The scoring system was developed by the same authors. Total score is obtained by summing up all items. Total score is ranging from 0 to 40 , with scores ranging from 0-7 considered as having very low level of perceived stress, scores from 8-11 as low level of perceived stress, scores from 12-15 as average level of perceived stress, scores from 16-20 as high level of perceived stress, and scores from 21 and over will reflect very high level of perceived stress ${ }^{(39)}$.Perceived stress scale has been tested for internal consistency $($ Cronbach's alpha $=0.87)$ and reliability $($ coefficient correlation $=0.85){ }^{(40)}$ 


\subsection{Method of Data Collection:}

- Official permission to conduct the study was obtained from the head of the Psychiatric Nursing and Mental health Department after explanation of the purpose of the study.

- Tools II\& III were translated into Arabic and tested for content validity by 5 experts in the fieldof Psychiatricnursing and necessary modifications were done.

- A pilot study was carried out on 20 students who were excluded from the study to test the feasibility and clarity of the tools.Accordingly, the necessary modifications were done.

-The reliability of Ryff"s psychological wellbeing scale,emotional skills/ competencequestionnaire and Perceived Stress Scalewere measured by test - retest on 20 psychiatric nursing students $(r .=0.87,0.88$ and 0.84$)$.

- The questionnaire was administered individually (in the presence of the researcher) to every student, inthe second semester (February 2019). It tooks about 15 minutes for each individual to complete it.

\section{Ethical Considerations:}

- Informed oral consent was obtained from the studied students after explaining the importance and aims of the study.

- Confidentiality of the obtained data was assured.

- Students' privacy and anonymity were considered and respected.

- The right to refuse to participate or to withdraw from the study was emphasized, after reassuring students that their responses would have no impact on their grades.

\subsection{Statistical Analysis:}

Data were coded, computerized and then analyzed using the Statistical Package for Social Sciences (SPSS) software package version 20.0. Descriptive statistics like number, percentage, minimum, maximum, means and standard deviations (SD) were used to describe and summarize data.For normally distributed quantitative variables,Student t-test was used to compare between two studied groups. F-test (ANOVA) to compare between more than two groups and Pearson coefficient to correlate between two normally distributed quantitative variables. Significance of the obtained results was judged at the $5 \%$ level.

\section{Results}

Table (I)shows the distribution of studied students (135) according to their socio demographic and academic characteristic. It appears from this table that the majority of the studied students $(83.7 \%)$ were females. aged between $20-25$ years, with a mean age of $21.84 \pm 1.08$ years. Considering the students' residency, the majority $92.6 \%$ of the studied students were living in urban areas. Regarding residency during the academic year, $88.9 \%$ were living with their families. The table also revealed that the majority $(91.9 \%)$ of the studied students were single. A large percentage $(80.7 \%)$ of the studied students had enough family income.

Concerning the studied students' grades in the previous academic year, nearly half of the studied students (48.9\%) obtained very good grade, and more than one third of them (34.8\%) obtained good grade. Only $1.5 \%$ of the studied students failed. With respect to participation in academic/ social activities, it can be seen that around one quarter of thestudied students $(23.7 \%)$ participated in academic/ social activities. Those who participated in music, poetry, drawing constituted $43.8 \%$, and one quarter of thestudied students $(25.0 \%)$ participated in sports. 
Table (I): Distribution of the studied students according to socio demographic and academic characteristic $(n=135)$

\begin{tabular}{|c|c|c|}
\hline Socio demographic data & No. & $\%$ \\
\hline $\begin{array}{c}\text { Gender } \\
\text { Male } \\
\text { Female } \\
\end{array}$ & $\begin{array}{c}22 \\
113\end{array}$ & $\begin{array}{l}16.3 \\
83.7\end{array}$ \\
\hline $\begin{array}{l}\text { Age (years) } \\
\quad<22 \\
\geq 22\end{array}$ & $\begin{array}{l}66 \\
69\end{array}$ & $\begin{array}{l}48.9 \\
51.1\end{array}$ \\
\hline $\begin{array}{l}\text { Min. - Max. } \\
\text { Mean } \pm \text { SD. }\end{array}$ & \multicolumn{2}{|c|}{$\begin{array}{c}20.0-25.0 \\
21.84 \pm 1.08\end{array}$} \\
\hline \begin{tabular}{|l|} 
Permanent residence \\
Town \\
Village \\
\end{tabular} & $\begin{array}{c}125 \\
10 \\
\end{array}$ & $\begin{array}{c}92.6 \\
7.4 \\
\end{array}$ \\
\hline $\begin{array}{l}\text { With those who live during the school year } \\
\text { With family } \\
\text { With relatives } \\
\text { University City } \\
\text { With colleagues and outside the university city } \\
\text { Alone }\end{array}$ & $\begin{array}{c}120 \\
2 \\
4 \\
7 \\
2 \\
\end{array}$ & $\begin{array}{c}88.9 \\
1.5 \\
3.0 \\
5.2 \\
1.5 \\
\end{array}$ \\
\hline \begin{tabular}{|l} 
Marital status \\
Single \\
Married \\
\end{tabular} & $\begin{array}{c}124 \\
11 \\
\end{array}$ & $\begin{array}{c}91.9 \\
8.1 \\
\end{array}$ \\
\hline $\begin{array}{l}\text { Monthly income } \\
\text { Enough } \\
\text { Not enough }\end{array}$ & $\begin{array}{c}109 \\
26\end{array}$ & $\begin{array}{l}80.7 \\
19.3\end{array}$ \\
\hline Academic characteristic & & \\
\hline $\begin{array}{l}\text { Year of enrollment } \\
\text { Fourth }\end{array}$ & 135 & 100.0 \\
\hline \begin{tabular}{|l|} 
Student's grade in previous academic year \\
Excellent \\
Very good \\
Good \\
Pass \\
Failure \\
\end{tabular} & $\begin{array}{c}10 \\
66 \\
47 \\
10 \\
2 \\
\end{array}$ & $\begin{array}{c}7.4 \\
48.9 \\
34.8 \\
7.4 \\
1.5 \\
\end{array}$ \\
\hline \begin{tabular}{|l|} 
Academic/ social support \\
Yes \\
No \\
\end{tabular} & $\begin{array}{c}32 \\
103 \\
\end{array}$ & $\begin{array}{l}23.7 \\
76.3\end{array}$ \\
\hline $\begin{array}{l}\text { If Yes }(\mathbf{n}=\mathbf{3 2}) \text { types of academic/ social support } \\
\text { Scout and camps } \\
\text { Trips } \\
\text { Music, Poetry, Drawing } \\
\text { Sports } \\
\text { Others } \\
\end{array}$ & $\begin{array}{c}3 \\
9 \\
14 \\
8 \\
9 \\
\end{array}$ & $\begin{array}{c}9.4 \\
6.7 \\
43.8 \\
25.0 \\
28.1 \\
\end{array}$ \\
\hline
\end{tabular}

Table (II) describes types and sources of social support provided to the studied students. The table reveals that more than three quarters of the studied students reported that they received emotional support, esteem support, and interaction support $(86.7 \%, 83.7 \%$, and $80.0 \%$ respectively). Regarding the sources of social support received, it can be observed that $93.0 \%$ of the studied students received social support from parents, and nearly half of them $(45.7 \%)$ received the social support from friends. 
Table (II)Distribution of the studied students according to types and sources of social support

\begin{tabular}{|l|c|c||}
\hline \multicolumn{1}{|c||}{$\begin{array}{c}\text { Types and sources of social support } \\
\text { (N= 135) }\end{array}$} & No \\
\hline Types of social support* & & \\
Emotional support & & \\
Esteem support & 117 & 86.7 \\
Interaction, Network support & 113 & 83.7 \\
Knowledge support & 108 & 80.0 \\
Financial support & 105 & 77.8 \\
Others & 90 & 66.7 \\
\hline Satisfaction with social support & 5 & 3.7 \\
Yes & 116 & 89.9 \\
No & 13 & 10.1 \\
& & \\
\hline (If ses) sources of social support** & No & $\%$ \\
(n=129) & & \\
\hline Parents & 120 & 93.0 \\
Friends & 59 & 45.7 \\
Husband, Wife & 12 & 9.3 \\
Lectutives & 16 & 12.4 \\
Others & 15 & 11.6 \\
\hline
\end{tabular}

*More than one type of social support.

** More than one source of social support.

Table (III)shows the descriptive analysis of subscales of emotional skills and competence of the studied students $(n=135)$. It can be observed that the mean scores of the studied students to manage and regulate their emotions was $63.70 \pm 10.79$, express and label it $63.89 \pm 12.54$ while the mean score for their skills to perceive and understand their own emotions was $59.56 \pm 11.68$. These reflect that the studiednursing students demonstrate a moderate degree of emotional skills and competence.

Table (III)Descriptive analysis of emotional skills and competence subscales of the studied students $(n=135)$.

\begin{tabular}{|r|r|r||}
\hline Subscales of emotional skills and competence & Total score & \% score \\
\hline Manage and regulate & & \\
Min. - Max. & $41.0-73.0$ & $39.06-89.06$ \\
Mean \pm SD. & $56.77 \pm 6.91$ & $63.70 \pm 10.79$ \\
\hline Express and label & & \\
Min. - Max. & $31.0-65.0$ & $30.36-91.07$ \\
Mean \pm SD. & $47.36 \pm 6.54$ & $59.56 \pm 11.68$ \\
\hline Perceive and understand & & $31.67-95.0$ \\
Min. - Max. & $34.0-72.0$ & $63.89 \pm 12.54$ \\
Mean \pm SD. & $53.00 \pm 7.53$ & \\
Oin. - Max. & $\mathbf{1 1 2 . 0}-\mathbf{2 0 3 . 0}$ & $\mathbf{3 7 . 2 2}-\mathbf{8 7 . 7 8}$ \\
Mean \pm SD. & $\mathbf{1 5 7 . 4 6} \pm \mathbf{1 9 . 2 9}$ & $\mathbf{6 2 . 4 8} \pm \mathbf{1 0 . 7 2}$ \\
\hline
\end{tabular}


Table (IV) presents the descriptive analysis of subscales of Ryff's psychological well-being (PWB) among the studied students $(n=135)$. It was noticed that the purpose in life, positive relations, and personal growth obtained the highest mean score $(65.71 \pm 19.21,64.78 \pm 17.43$, and $63.96 \pm 18.79$, respectively). Whereas the students' mean score of environmental mastery, autonomy, and self-acceptance had the lowest mean score (58.92 $\pm 14.54,58.01 \pm 14.73$, and $57.93 \pm 19.22$, respectively).

Table (IV): Descriptive analysis of subscales of Ryff's psychological well-being scales (PWB) among the studied students $(\mathbf{n}=\mathbf{1 3 5})$

\begin{tabular}{|c|c|c|}
\hline Subscales of Ryff's Psychological Well-Being (PWB) & Total score & $\%$ score \\
\hline Autonomy & & \\
\hline Min. - Max. & $16.0-40.0$ & $25.71-94.29$ \\
\hline Mean \pm SD. & $27.30 \pm 5.16$ & $58.01 \pm 14.73$ \\
\hline \multicolumn{3}{|l|}{ Environmentalmastery } \\
\hline Min. - Max. & $12.0-40.0$ & $14.29-94.29$ \\
\hline Mean \pm SD. & $27.62 \pm 5.09$ & $58.92 \pm 14.54$ \\
\hline \multicolumn{3}{|l|}{ PersonalGrowth } \\
\hline Min. - Max. & $13.0-42.0$ & $17.14-100.0$ \\
\hline Mean \pm SD. & $29.39 \pm 6.58$ & $63.96 \pm 18.79$ \\
\hline \multicolumn{3}{|l|}{ Positive Relations } \\
\hline Min. - Max. & $10.0-42.0$ & $8.57-100.0$ \\
\hline Mean \pm SD. & $29.67 \pm 6.10$ & $64.78 \pm 17.43$ \\
\hline \multicolumn{3}{|l|}{ Purpose in life } \\
\hline Min. - Max. & $8.0-42.0$ & $2.86-100.0$ \\
\hline Mean \pm SD. & $30.0 \pm 6.72$ & $65.71 \pm 19.21$ \\
\hline \multicolumn{3}{|l|}{ Self-acceptance } \\
\hline Min. - Max. & $12.0-42.0$ & $14.29-100.0$ \\
\hline Mean \pm SD. & $27.27 \pm 6.73$ & $57.93 \pm 19.22$ \\
\hline Overall & & \\
\hline Min. - Max. & $81.0-235.0$ & $18.57-91.90$ \\
\hline Mean \pm SD. & $171.26 \pm 27.06$ & $61.55 \pm 12.89$ \\
\hline
\end{tabular}

Table (V)displays the distribution of the studied students according to perceived stress scale (PSS) $(n=135)$. It can be observed that more than half of the studied students $(55.6 \%)$ had very high level of perceived stress. Furthermore, nearly one third of them (30.4\%) demonstrate high level of perceived stress. Only, 2.2\% and $0.7 \%$ respectively, had low and very low level of perceived stress. 
Table (V): Distribution of the studied students according to Perceived Stress Scale (PSS) (n=135)

\begin{tabular}{|r|c|c|}
\hline \multicolumn{1}{|c|}{ Perceived stress scale } & No. & \% \\
\hline Very low level of perceived stress $(0-7)$ & 1 & 0.7 \\
Low level of perceived stress $(8-11)$ & 3 & 2.2 \\
Average level of perceived stress $(12-15)$ & 15 & 11.1 \\
High level of perceived stress $(16-20)$ & 41 & 30.4 \\
Very high level of perceived stress $(\geq 21)$ & 75 & 55.6 \\
\hline Total score & & \\
Min. - Max. & & \\
Mean \pm SD. & $21.0-37.0$ \\
\% score & \multicolumn{2}{|c|}{} \\
Min. Max. & $10.0-92.50$ \\
Mean \pm SD. & $54.59 \pm 14.77$ \\
\hline
\end{tabular}

Table (VI) illustrates the relation between overall emotional skills and competence, Ryff's Psychological Well-Being Scales (PWB)and Perceived Stress Scale (PSS) with types of social support among the studied students. From this table it can be concluded that, the mean scores of the overall emotional skills and competence, Ryff's Psychological Well-Being Scales (PWB)and Perceived Stress Scale (PSS) didn't show any statistical significant relation with the studied students' different types of perceived social support $(\mathrm{F}=0.259, \mathrm{P}=0.935, \mathrm{~F}=$ $0.594, \mathrm{P}=0.705, \mathrm{~F}=0.474, \mathrm{P}=0.796$, respectively).

Table (VI): Relation between overall emotional skills and competence,Ryff's Psychological Well-Being Scales (PWB)and Perceived Stress Scale (PSS) with types of social support.

\begin{tabular}{|l|c|c|c||}
\hline $\begin{array}{l}\text { Types of social } \\
\text { support }\end{array}$ & $\begin{array}{c}\text { Overall emotional skills } \\
\text { and competence }\end{array}$ & $\begin{array}{c}\text { Overall Ryff's Psychological } \\
\text { Well-Being Scales(PWB) }\end{array}$ & $\begin{array}{c}\text { Overall Perceived } \\
\text { Stress Scale (PSS) }\end{array}$ \\
\cline { 2 - 4 } & Mean \pm SD. & Mean \pm SD. & Mean \pm SD. \\
\hline Emotional support & $63.07 \pm 10.30$ & $62.30 \pm 13.19$ & $53.31 \pm 14.61$ \\
Esteem support & $64.28 \pm 9.92$ & $64.06 \pm 11.73$ & $52.17 \pm 13.67$ \\
Interaction, \\
Network support \\
Knowledge support
\end{tabular}

F: F for ANOVA test

Table (VII) reveals the correlation matrix between the overall component of emotional skills and competence, Ryff's Psychological Well-Being Scales (PWB) and Perceived Stress Scale (PSS) among the studied students $(n=135)$. From this table it can be observed that there is a strong positive correlations were found between the overall emotional skills / competence and the overall Ryff's psychological well-Being scales $(\mathrm{r}=0.423, \mathrm{P}=$ 0.001). Also, there is a negative correlations were found between the overall emotional skills / competence and the overall Ryff's psychological well-Being and Perceived Stress scales $(r=-0.309, P=0.001$, and $r=-0.538, P=$ 0.001 respectively). 
Table (VII):Correlation Matrix between Subscales of Emotional skills and competence, Ryff's Psychological Well-Being Scales (PWB) and Perceived Stress Scale (PSS) (n=135).

\begin{tabular}{|c|c|c|c|c|c|c|c|c|c|c|c|c|}
\hline & \multicolumn{4}{|c|}{ Emotional skills and competence } & \multicolumn{7}{|c|}{ Ryff's Psychological Well-Being Scales (PWB) } & \multirow[b]{2}{*}{\begin{tabular}{|c|} 
Perceived \\
Stress Scale \\
(PSS)
\end{tabular}} \\
\hline & \begin{tabular}{|c|}
$\begin{array}{c}\text { Manage } \\
\text { and } \\
\text { regulate }\end{array}$ \\
\end{tabular} & $\begin{array}{c}\text { Express } \\
\text { and } \\
\text { label }\end{array}$ & \begin{tabular}{|c|} 
Perceive and \\
understand
\end{tabular} & Overall & Autonomy & $\begin{array}{c}\text { Environmental } \\
\text { mastery }\end{array}$ & $\begin{array}{c}\text { Personal } \\
\text { growth }\end{array}$ & $\begin{array}{c}\text { Positive } \\
\text { relations }\end{array}$ & $\begin{array}{c}\text { Purpose } \\
\text { in life }\end{array}$ & $\left|\begin{array}{c}\text { Self- } \\
\text { acceptance }\end{array}\right|$ & Overall & \\
\hline $\begin{array}{l}\text { Manage and } \\
\text { regulate }\end{array}$ & & & & & & & & & & & & \\
\hline Express and label & \begin{tabular}{|c|}
$0.721^{*}$ \\
$<0.001^{*}$ \\
\end{tabular} & & & & & & & & & & & \\
\hline $\begin{array}{l}\text { Perceive and } \\
\text { understand }\end{array}$ & \begin{tabular}{|c|}
$0.811^{*}$ \\
$<0.001^{*}$ \\
\end{tabular} & $\begin{array}{c}0.768^{*} \\
<0.001^{*} \\
\end{array}$ & & & & & & & & & & \\
\hline \begin{tabular}{|c|} 
Overall emotional \\
skills and \\
competence
\end{tabular} & \begin{tabular}{|l|}
$0.919^{*}$ \\
$<0.001^{*}$ \\
\end{tabular} & \begin{tabular}{|l|}
$0.897^{*}$ \\
$<0.001^{*}$
\end{tabular} & $\begin{array}{l}0.941^{*} \\
<0.001^{*}\end{array}$ & & & & & & & & & \\
\hline Autonomy & $\begin{array}{l}0.269^{*} \\
0.002^{*} \\
\end{array}$ & \begin{tabular}{|c|}
$0.327^{*}$ \\
$<0.001^{*}$ \\
\end{tabular} & $\begin{array}{l}0.327^{*} \\
<0.001^{*} \\
\end{array}$ & \begin{tabular}{|c|}
$0.335^{*}$ \\
$<0.001^{*}$ \\
\end{tabular} & & & & & & & & \\
\hline $\begin{array}{c}\text { Environmental } \\
\text { mastery }\end{array}$ & $\begin{array}{l}0.205^{*} \\
0.017^{*}\end{array}$ & $\begin{array}{c}0.317^{*} \\
<0.001^{*} \\
\end{array}$ & $\begin{array}{l}0.187^{*} \\
0.030^{*}\end{array}$ & $\begin{array}{l}0.254^{*} \\
0.003^{*}\end{array}$ & $\begin{array}{c}0.443^{*} \\
<0.001 * \\
\end{array}$ & & & & & & & \\
\hline Personal growth & $\begin{array}{l}0.197^{*} \\
0.022^{*}\end{array}$ & $\begin{array}{c}0.304^{*} \\
<0.001^{*}\end{array}$ & $\begin{array}{l}0.190^{*} \\
0.027^{*}\end{array}$ & $\begin{array}{l}0.248^{*} \\
0.004^{*}\end{array}$ & $\begin{array}{l}0.422^{*} \\
<0.001^{*}\end{array}$ & $\begin{array}{l}0.529^{*} \\
<0.001^{*}\end{array}$ & & & & & & \\
\hline Positive relations $r$ & $\begin{array}{l}0.257^{*} \\
0.003^{*}\end{array}$ & $\begin{array}{c}0.301^{*} \\
<0.001^{*}\end{array}$ & $\begin{array}{c}0.305^{*} \\
<0.001^{*}\end{array}$ & $\begin{array}{c}0.313^{*} \\
<0.001^{*}\end{array}$ & $\begin{array}{c}0.473^{*} \\
<0.001^{*}\end{array}$ & $\begin{array}{c}0.452^{*} \\
<0.001^{*}\end{array}$ & \begin{tabular}{|c|}
$0.397^{*}$ \\
$<0.001^{*}$ \\
\end{tabular} & & & & & \\
\hline Purpose in life & $\begin{array}{l}0.240^{*} \\
0.005^{*}\end{array}$ & \begin{tabular}{|c|}
$0.307^{*}$ \\
$<0.001^{*}$ \\
\end{tabular} & $\begin{array}{l}0.246^{*} \\
0.004^{*} \\
\end{array}$ & $\begin{array}{l}0.286^{*} \\
0.001^{*} \\
\end{array}$ & $\begin{array}{l}0.293^{*} \\
0.001^{*} \\
\end{array}$ & $\begin{array}{c}0.341^{*} \\
<0.001 * \\
\end{array}$ & \begin{tabular}{|c|}
$0.573 *$ \\
$<0.001 *$ \\
\end{tabular} & \begin{tabular}{|c|}
$0.430^{*}$ \\
$<0.001^{*}$ \\
\end{tabular} & & & & \\
\hline Self-acceptance & \begin{tabular}{|c|}
$0.328^{*}$ \\
$<0.001^{*}$ \\
\end{tabular} & $\begin{array}{c}0.469^{*} \\
<0.001^{*} \\
\end{array}$ & $\begin{array}{c}0.421^{*} \\
<0.001^{*} \\
\end{array}$ & $\begin{array}{c}0.441^{*} \\
0.001 * \\
\end{array}$ & $\begin{array}{c}0.408^{*} \\
<0.001^{*} \\
\end{array}$ & $\begin{array}{c}0.461^{*} \\
<0.001 * \\
\end{array}$ & \begin{tabular}{|c|}
$0.485^{*}$ \\
$<0.001 *$ \\
\end{tabular} & \begin{tabular}{|c|}
$0.523^{*}$ \\
$<0.001^{*}$ \\
\end{tabular} & \begin{tabular}{|c|}
$0.625 *$ \\
$<0.001 *$ \\
\end{tabular} & & & \\
\hline \begin{tabular}{|c|} 
Overall Ryff's \\
Psychological Well- \\
Being Scales \\
(PWB) \\
\end{tabular} & $<0.001^{*}$ & $0.456^{*}$ & $0.378^{*}$ & $0.423 *$ & $<0.001^{*}$ & $0.702^{*}$ & \begin{tabular}{|c|}
$0.776^{*}$ \\
$<0.001^{*}$ \\
\end{tabular} & \begin{tabular}{|l|}
$0.734^{*}$ \\
$<0.001^{*}$ \\
\end{tabular} & $<0.001 *$ & $\begin{array}{l}0.804^{*} \\
<0.001^{*}\end{array}$ & & \\
\hline $\begin{array}{c}\text { Perceived Stress } \\
\text { Scale (PSS) }\end{array}$ & \begin{tabular}{|l}
$-0.286^{*}$ \\
$0.001 *$
\end{tabular} & $\begin{array}{l}-0.302^{*} \\
<0.001^{*}\end{array}$ & $\begin{array}{l}-0.267^{*} \\
0.002^{*}\end{array}$ & \begin{tabular}{|l|}
$-0.309 *$ \\
$0.001 *$
\end{tabular} & $\begin{array}{l}-0.337^{*} \\
<0.001^{*}\end{array}$ & $\begin{array}{l}-0.447^{*} \\
<0.001^{*}\end{array}$ & \begin{tabular}{|l|}
$-0.396^{*}$ \\
$<0.001^{*}$
\end{tabular} & $\begin{array}{l}-0.350^{*} \\
<0.001^{*}\end{array}$ & $\begin{array}{l}-0.327^{*} \\
<0.001^{*}\end{array}$ & $\begin{array}{l}-0.535^{*} \\
<0.001^{*}\end{array}$ & \begin{tabular}{|c|}
$-0.538^{*}$ \\
$<0.001 *$
\end{tabular} & \\
\hline
\end{tabular}

\section{r: Pearson coefficient}

* Statistically significant at $\mathrm{p} \leq 0.05$

\section{Discussion}

University nursing students experience higher levels of academic stress than those of other disciplines. Sources of stress for nursing students extend beyond academic stress, to stressful events that are independent of their clinical experience which has detrimental effects on their well-being and leads to psychological distress. ${ }^{(14)}$ Researches revealed that nursing students can overcome these feelings if they increased their ability to manage and get into the sphere of their own emotional relations. ${ }^{(41)}$

Emotion is crucial for nursing practice because it affects the ability to think clearly, make proper judgments and decision- making on the patient care and interpersonal relationships with colleagues. ${ }^{(42)}$ Being emotionally competent help students to cope with their stressors and have the feeling of well-being either physical or psychological. ${ }^{(43)}$

The results of the present study revealed that the majority of the undergraduate nursing students had either very high or high level of perceived stress as shown in (Table IV). This result may be in part influenced by several causal factors. The firstalternative factor to be consideredis that the majority of the nursing students reporting that they are feel more anxious and feared of being harmed or sexually assaulted by the patient, which develop the sense of fear and insecurity for them during their clinical training.

No doubt that the myths and misconceptions attached to mental illnesses and mental health settings are major contributors to this finding. Moreover the stigma related to mental illness and patients with psychiatric disorders are perpetuated by the media which portrays negatively psychiatric treatment facilities and their patients. ${ }^{(44)}$ This interpretation was supported by Alshowkan and Kamel $(2016)^{(45)}$ who revealed that the nursing students clearly identified that the initial clinical experience was stressful, fearful and anxiety provoking for them. Such negative emotions were attributed to the lack of knowledge and initial negative view of mental illness.Cheung et al $2016^{(46)}$,also claimed that the level of stress, anxiety and depression were significantly increased among baccalaureate nursing students.

Stress usually leads to emotional exhaustion and the individual feels emotionally drained by intense contact with 
others. ${ }^{(23)}$ The ability to regulate and mange one's emotions as well as being emotionally competent is a good strategy to cope with stress. ${ }^{(47)}$ This is especially true knowing that the studied nursing students had a moderate degree of emotional skills/ competency and a high level of perceived stress with a negative significant correlation between them. This is in the same line of results of Spanish study indicating that emotionalcompetencemayincreasethecapacity to cope with stress. ${ }^{(46)}$ Moreover other study done by Nelis et al $(2011),{ }^{(42)}$ confirmed that emotional competence is regarded as an affect-related skill, which refers to the ability to understand, manage, and express the social and emotional aspects of life in ways that enable one to cope with stressful and emotionally laden situations. Other study (Egypt, 2016) ${ }^{(47)}$ reported that the students who have high emotional intelligence are better in managing the emotions evoked by the demands of their nursing program and, therefore, experience less stress.

Evidences support that effective coping with stress and having emotional skill/competence helps individuals in developing psychological well-being and satisfaction with their life which are indicators of good mental functioning. ${ }^{(48,49)}$ These results lent further support for the present study findings, in which strong positive correlations were found between the overall emotional skills / competence and the overall Ryff's psychological well-Being scales. On the contrary, the overall perceived stress was negatively and strongly correlated withemotional skills / competence and Psychological well being. This means that high level of emotional skills/competence and well being indicates lower level of perceived stress. (Table 7). This goes with the findings obtained by Chow K et al (2018) ${ }^{(50)}$ whorevealed that senior students had significantly higher level of perceived well-being with a significant positive correlation between coping resilient and perceived well-being. These also could affirm and verify the increased level of perceived stress among the undergraduates of this study.

A significant negative correlation between the studied nursing students' psychological well being and their Stress level was determined in the present study. (Table VII) This may be explained as the majority of the studied nursing students had enough income in addition to the social support they received and their academic achievement; these variables may help them to be psychologically well even they face their academic and clinical training stress.

As it was cited in the results of the present study, that the studied nursing students obtained the highest mean score of well-being in three areas namely; the purpose in life, positive relations, and personal growth(Table IV). These results could be partly justified by the oral declare of the studied students, that they wish to finish their studying time, get job at good hospital, start working,and have money to achieve better life. In addition, more than three quarters of the studied students reported that they received either emotional, self esteem or interaction support from their families and friendswhich may contribute to their psychological well-being even though there was no statistical significant correlation between wellbeing and this variable. This is consistent with a study done by Lekshmi M et al in India (2017) ${ }^{(48)}$ which indicate that more than two third of their studied adolescents have wellbeing and this is associated with their family support and practicing extracurricular activities. Therefore, nursing educators have an integral role in furnishing their nursing students to use adaptive ways of appraisal of stressful situations, buffer the deleterious impact of stress and deliver emotionally competent nursing practice.

It is not surprising in the current study that there is significant positive correlation between the overallemotional skills/ competence and theoverallpsychological well-beingamong the studied subjects(Table VII).This was supported byRashida Masrat1(2015) ${ }^{(51)}$ who postulateda significant positive correlation between Emotional Competence and Overall Well-being. The study stated that emotional competence let individuals express their inner feelings without any suppression. Also, emotional competence contributes to the achievement of both intrapersonal (e.g., individual well-being) and interpersonal (e.g., maintenance of important social relationships) well-being. ${ }^{(52)}$ Another study done by Nelis et al ( 2011) ${ }^{(42)}$ showed that the development of emotional competence brought about positive changes in psychological well-being, subjective health, quality of social relationships, and employability among undergraduate students. The effect sizes were sufficiently large for the changes to be considered as meaningful in people's lives.

Taken together, nursing students face many stressors through their academic experiences. Mastering effective emotional skills / competence play a vital role in managing their emotions, decreasing their level of stress and improving their psychological well-being.

Emotional competence takes too long to acquire and that emotional competence is the product of life experience alongside development within nursing students' potential practice. ${ }^{(52)}$ Therefore, there is a tremendous need for nursing lecturers to arm the undergraduates with the educational curriculum that empowering them toward upgrading their emotional skills and psychological well-being, to struggle against the successive waves of daily stressors, hence they can have meaningful life. 


\section{Conclusion:}

According to the findings of the present study, it can be concluded thatmore than half of the studied nursing students had very high level of perceived stressand demonstrated a moderate degree of emotional skills and competence.In addition, the purpose in life, positive relations, and personal growth of psychological well- being obtained the highest mean score, whereas the students' mean score of environmental mastery, autonomy, and selfacceptance had the lowest mean score. A strong positive correlationwas found between the overall emotional skills and competence and the overall Ryff's psychological well-Being scales, andastrong negative correlation was found between the overall emotional skills and competence and the overall Ryff's psychological well-Being scales and perceived stress scale.

\section{Recommendations:}

The followings are the main recommendations yielded by this study:

- $\quad$ Nursing students' psychological and emotional competence could be promoted through implementation of emotional hygiene program, that teach the nursing students to care for their own emotions and didn't leave them injured or untreated, because it will get worse.

Enhancement of the nursing students' psychological and emotional competence should be incorporated in the nursing curricula to teach the nursing students adaptive coping strategies

- $\quad$ Enhancement of the activities of counseling center geared tohelp the nursing students to deal with psychological stresses, and mitigated its effects in the case of exposure to such stresses.

- $\quad$ Nursing educators must be perceptive of common stressors that might face nursing studentsduring nursing education and training. This could, in turn, boost up their coping strategies to deal with the different stressors.

- $\quad$ Further studies are required to determine the perceived stress levels of nursing students in relation to various courses, so that the faculty can provide a graduate professional nurse able to adapt to ever challenges at different health settings.

\section{Limitations ofthe Study}

- $\quad$ The study was conducted in one nursing setting, which may affect the generalization of the study results to other nursing institutions.

\section{Despite these limitations, the present study was offset by points of strengths:}

- $\quad$ All of the nursing students in this study were highly motivated to participate in the study.

- $\quad$ Studying the correlational nature between such variables could acts asa useful adjunct to improve the nursing students' academic achievementand clinical practice.As well,itcould reduce the risk of experiencing emotional distress during the academicyears.

\section{Acknowledgement}

The researchers are grateful to the graduate students who were appreciatedto participate in this study.

\section{References:}

1- Sarafis P, Rousaki E, Tsounis A, Malliarou M, Lahana L, Bamidis P, Niakas D, Papastavrou E.The impact of occupational stress on nurses' caring behaviors and their health-related quality of life.BMC Nursing 2016; 27:15-6.

$$
\text { 2- Jordan T, Khubchandani J, Wiblishauser } \quad \text { M. }
$$
The impact of perceived stress and coping adequacy onthe health of nurses:a pilot investigation. Nursing Research and Practice 2016:1-11.

3- Sharif F, Masoumi S. A qualitative study of nursing student experience of clinical practice. BMC Nursing 2005;9;4:6.

4- $\quad$ ForushaniN,Besharat M. Relation between emotional Intelligence and perceived stress among female students. Procedia-Social and Behavioral Sciences2011; 30, 1109-12. 
5- Maharaj S, Lees T, Lal S. Prevalence and risk factors of depression, anxiety, and stress in a cohort of Australian nurses. International Journal of Environmental Research and Public Health 2018;16(1):118.

6- $\quad$ Criollo F, Escobedo J, Ruiz G. Stress in nursing university students and mental health. Available at: file://C:/Users/HP/Downloads/58763.pdf. Retrieved on June, 2019.

7- $\quad$ Rees C, Heritage B, Moisson R, Chamberlain D, Cusack L, Anderson J, Terry V, Rogers C, Hemsworth D, Cross W, Hegney D. Can we predict burnout among student nurses? an exploration of the icwr1 model of individual psychological resilience.Frontiers of Psychology 2016;7:1-27.

8- $\quad$ Tung Y, Lo K, Ho R, Tam W. Prevalence of depression among nursing students: A systematic review and meta-analysis. Nurse Education Today. 2018;63:119-29.

9- Koinis A, Giannou V, Drantaki V, Angelaina S, Stratou $\quad$ E, Saridi $\quad$ M. The impact of healthcare workers job environment on their mental-emotional health. coping strategies: the case ofa Local General Hospital. Health PsychologyResearch. 2015 13;3(1):1984.

10- $\quad$ Faremia F, Olatubib M, AdeniyicK,SalaudO. Assessment of occupational related stress among nurses in two selectedhospitals in a city southwestern Nigeria. International Journal of Africa Nursing Sciences 2019; (10): 68-73.

11- Shalaby S, AlDilh S. Exploring the relationship between perceived stress and academic achievement among critical care nursing students. Athens Journal of Health 2018;2(4):283-96.

12- Amr A, El-Gilany A, El-Moafee H, Salama L, Jimenez Stress among Mansoura (Egypt) baccalaureate nursing students. The Pan African Medical Journal 2011;8(26):117.

13- El-Gilany A, Amr M, Hammad S. Perceived stress among male medical students in Egypt and Saudi Arabia: effect of socio-demographic factors. Annals Saudi Medicine 2008;28(6):442-8.

14- Shanmugam G, Jasmindebora S, BabaV.Impact of stress on nursing students. International Journal of Innovative Research and Advanced Studies 2017; 4(4):1-5.

15- Gibbons C. Stress, coping and burn-out in nursing students. International Journal of Nursing Studies 2010;47(10):1299-309.

16- Alyousef S. Psychosocial stress factors among mental health nursing students in KSA. Journal of Taibah University Medical Science 2018 13;14(1):60-6.

17- Ryff C. Happiness is everything, or is it? Explorations on the meaning of psychological well-being. Journal of Personality and Social Psychology 1989; 57(6): 1069-81.

18- Monteiro $\quad$ N, Balogun S, Oratile K. Managing stress: the influence of gender, age and emotion regulation on coping among university students in Botswana. International Journal of Adolescence and Youth. 2014;19(2):153-73.

19- Ratanasiripong P, Wang C. Psychological well-being of Thai nursing students. Nurse Educ Today 2011;31(4):412-6.

20- Zaki M, Sayed F, Elattar N. Relationship between Face book Use and Psychological Well-being for Baccalaureate Nursing Students at Benha University. IOSR Journal of Nursing and Health Science2018;7(1):1-9. 
21- Udhayakumar P. Illango. Psychological wellbeing among college students. Journal of Social Work Education and Practice 2018;3(2):79-89.

22- Raghubir A. Emotional intelligence in professional nursing practice: A concept review using Rodgers's evolutionary analysis approach.International Journal of Nursing Science 2018; 5(2):126-30.

23- Lau P, Wu F. Emotional competence as a positive youth development construct: a conceptual review. The ScientificWorldJournal 2012;1-8.

24- Bhat R, Khan S. Emotional competence: review. National Journal of Multidisciplinary Research and Development2018;3(1): 44-9.

25- Gómez-Díaz M, Delgado-Gómez M, Gómez-Sánchez R. Education, emotions and health: emotional education in nursing. Procedia-Social and Behavioral Sciences 2017;237: 492-8.

26- Wodwaski N. The influence of caring and emotional intelligence among first-year Baccalaureate nursing students. International Journal of Healing and Caring 2018, 18(3):1-12.

27- DenhamS, BrownC. Plays Nice With Others": Social-emotional learning and academic success. Early Education and Development 2010;21(5):652-80.

28- Social and Emotional Skills Well-being, connectedness and success. Available at: http://www.oecd.org/education/school/UPDATED.pdf. Retrieved onAugust, 2019.

29- Andrews D, Wan T. The importance of mental health to the experience of job strain: an evidence-guided approach to improve retention. Journal of Nursing Management 2009;17:340-51.

30- $\quad$ Parker J, Creque R, Barnhart D, Harris J, Majeski S, Wood L, Bond B, Hogan M.Academic achievement in high school: Does emotional intelligence matter?.Personality and Individual Differences 2004;37(7):1321-30.

31- Durlak J, Weissberg R, Dymnicki A, Taylor R, Schellinger K. The impact of enhancing students' social and emotional learning: A meta-analysis of school-based universal interventions. Child Development2011; 82: 405-32.

32- Ramadan F, YakoutR. Psychological wellbeing and communication styles among medical-surgical nursing students. IOSR Journal of Nursing and Health Science 2017;6 (1): 75-85.

33- Academic achievement in high school: Does emotional intelligence matter?. Available at: https://www.researchgate.net/publication/223077353_Academic_achievement_in_high_school_Does_emotional _intelligence_matter.Retrieved onOctober, 2019.

34- Blanco C, Okuda M, Wright C, Hasin D, Grant B, Liu S, Olfson, M.Mental health of college students and their non-college-attending peers: results from thenational epidemiologic study on alcohol and related conditions. Archives of General Psychiatry 2008; 65(12): 1429-37.

35- Graan A, Williams M, Koen M. Professional nurses' understanding of clinical judgement: A contextual inquiry. Health SA Gesondheid 2016;21: 280-93.

36- Ryff C, SingerB. Best news yet on the six-factor model of wellbeing. SocialscienceResearch 200635(4):1103-19.

37- Takšić V. The importance of emotional intelligence (competence) in positive psychology. Paper presented at the First International Positive Psychology Summit, Washington, DC, October 4-6; 2002. 
38- Cohen S, Kamarck T, Mermelstein R. A global measure of perceived stress. Journal of Health and Social behavior 1983;4(24):385-95.

39- $\quad$ Cohen S, Williamson G. Perceived stress in probability sample. The social psychology of health, USA: Newbury Park Company, 1988;31-67.

40- Alzohary N. Relationship between ego resilience, perceived stress, and life satisfaction among Faculty nursing students, Damanhour University. Unpublished Master thesis. University of Alexandria, Faculty of Nursing, Alexandria, 2016.

41- Smith K, Profetto M and Cummings G. Emotional Intelligence and Nursing: An Integrative literature Review. International Journal of Nursing Studies 2009; 46(12):1624-1636.

42- $\quad$ Nelis D,Kotsou I, Quoidbach J, Hansenne M, Weytens F. Increasing Emotional Competence Improves Psychological and Physical WellBeing, Social Relationships, and Employability. Emotion 2011; 11(2):354-66.

43- $\quad$ Foltz MDP, Logsdon C. Reducing Stigma Related to Mental Disorders: Initiatives, Interventions, and Recommendations for Nursing. Archives of Psychiatric Nursing 2009; 23 (1): 32-40.

44- Alshowkan A, Kamel N. Nursing Student Experiences Of Psychiatric Clinical Practice A Qualitative Study. IOSR Journal of Nursing and Health Science 2016; 5(3): 60-67.

45- $\quad$ Cheung T Wong S, Wong K, Law L, Ng K, Tong M and Yip P. Depression, Anxiety and Symptoms of Stress among Baccalaureate Nursing Students in Hong Kong: A Cross-Sectional Study. Int. J. Environ. Res. Public Health 2016; 13: 779.

46- $\quad$ Rey L, Extremera N, Pena M. Emotional competence relating to perceived stress and burnout in Spanish teachers: a mediator model. PeerJ 2106.

47- Afifi M, Shehata A, PhD2, Abdalaziz E. Emotional Intelligence, Self- Efficacy and Academic Performance among University Students. IOSR Journal of Nursing and Health Science 2016; 5(3): 74-81.

48- $\quad$ Lekshmi MS, Sreeja I, Premini S. Emotional Intelligence and Wellbeing among Adolescents. Int. J. Nur. Edu. and Research. 2018; 6(2): 145-150.

49- $\quad$ Por J, Barriball L, Fitzpatrick J, Roberts J. Emotional intelligence: its relationship to stress, coping, wellbeing and professional performance in nursing students. Nurse Educ Today 2011;31(8):855-60.

50- Chow K, Tang W, Chan W, Sit J. Kai, Chan S. Resilience and well-being of university nursing students in Hong Kong: a cross-sectional study. BMC Medical Education 2018; 18(13): 3-8.

51- Masrat R, Wani M, Dr. Alam S. Influence of Emotional Competence on Well-being among Adolescents. The International Journal of Indian Psychology 2015; 2(3): 142-156.

52- Wilson S, Carryer J. Emotional competence and Nursing Education: A New Zealand Study. Nursing Praxis in New Zealand 2008. 24(1): 36-47. 